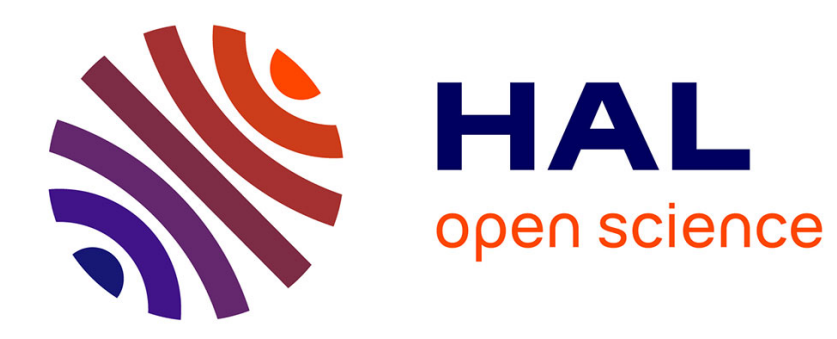

\title{
On the fourth derivative test for exponential sums
}

Olivier Robert

\section{To cite this version:}

Olivier Robert. On the fourth derivative test for exponential sums. Forum Mathematicum, 2016, 28 (2), pp.403-404. 10.1515/forum-2014-0216 . hal-01464788

\section{HAL Id: hal-01464788 \\ https://hal.science/hal-01464788}

Submitted on 12 Jun 2018

HAL is a multi-disciplinary open access archive for the deposit and dissemination of scientific research documents, whether they are published or not. The documents may come from teaching and research institutions in France or abroad, or from public or private research centers.
L'archive ouverte pluridisciplinaire HAL, est destinée au dépôt et à la diffusion de documents scientifiques de niveau recherche, publiés ou non, émanant des établissements d'enseignement et de recherche français ou étrangers, des laboratoires publics ou privés. 


\title{
On the fourth derivative test for exponential sums
}

\author{
Olivier Robert
}

\begin{abstract}
We give an upper bound for the exponential sum $\sum_{m=1}^{M} \exp (2 i \pi f(m))$ where $f$ is a real valued function whose fourth derivative has the order of magnitude $\lambda>0$ small. Van der Corput's classical bound, in terms of $M$ and $\lambda$ only, involves the exponent $1 / 14$. We show how this exponent may be replaced by any $\theta<1 / 12$ without further hypotheses. The proof uses a recent result by Wooley on the cubic Vinogradov system.
\end{abstract}

Let $C \geq 1$ be a real constant fixed once and for all. Let $a \in \mathbb{R}, M \in \mathbb{N}$ with $M \geq 10$. Let $0<\lambda_{4}<1 / 10$ be a real number and let $f:[a, a+M] \rightarrow \mathbb{R}$ be a $C^{4}$ function such that

$$
\lambda_{4} \leq\left|f^{(4)}(x)\right| \leq C \lambda_{4} \text { for } x \in[a, a+M] .
$$

We are interested in bounding the exponential sum

$$
S_{a, M}(f):=\sum_{a<m \leq a+M} e(f(m)),
$$

with the usual notation $e(t):=e^{2 i \pi t}$ for $t \in \mathbb{R}$. Under the previous assumptions, van der Corput's result asserts that setting $\theta_{4}=1 / 14$ and $\beta_{4}=4 / 7$, one has

$$
S_{a, M}(f) \ll_{C} M \lambda_{4}^{\theta_{4}}
$$

uniformly for $a \in \mathbb{R}, M \geq \lambda_{4}^{-\beta_{4}}$ and $f$ satisfying (1).

The purpose of this paper is to improve on the exponent $\theta_{4}$ in (3). Our result is the following.

Theorem 1 Let $a \in \mathbb{R}, M \in \mathbb{N}$ with $M \geq 10$. Let $0<\lambda_{4}<1 / 10$ be a real number and let $f:[a, a+M] \rightarrow \mathbb{R}$ be a $C^{4}$ function satisfying (1). Then for each $\varepsilon>0$, and with the notation (2), one has

$$
S_{a, M}(f) \ll_{C, \varepsilon} M^{1+\varepsilon} \lambda_{4}^{1 / 12}+M^{\frac{11}{12}+\varepsilon}
$$

uniformly for $a \in \mathbb{R}, M \geq \lambda_{4}^{-3 / 5}$ and $f$ satisfying (1).

Remark. Theorem 1 is not the first improvement of Van der Corput's result. Here is a brief history of these results under the hypothesis (1) alone : 
- Sargos [4] proved that for $\theta_{4}=1 / 14, \beta_{4}$ may be replaced by $3 / 7$. Moreover, in the same paper, he also proved that $\theta_{4}$ could be replaced by any $\theta<\frac{3}{40}$ provided that $\beta_{4}$ is replaced by $3 / 5$.

- Robert \& Sargos [1] proved $\theta_{4}$ may be replaced by any $\theta<\frac{1}{13}$ provided that $\beta_{4}$ is replaced by $8 / 13$.

Note that our Theorem 1 implies that $\theta_{4}$ may be replaced by any $\theta<1 / 12$ provided that $\beta_{4}$ is replaced by 1 .

It should also be mentioned that more generally when $k \geq 2$ is fixed, van der Corput proved that if $f:[a, a+M] \rightarrow \mathbb{R}$ is $C^{k}$ such that $\lambda_{k} \leq\left|f^{(k)}(x)\right| \leq C \lambda_{k}$, then $S_{a, M}(f) \ll_{C} M \lambda_{k}^{\theta_{k}}$ for $M \geq \lambda_{k}^{-\beta_{k}}$ with $\theta_{k}:=1 /\left(2^{k}-2\right), \beta_{k}:=2^{k-1} /\left(2^{k}-\right.$ $2)$. For $k=2$, the example of the Gauss sums shows at once that $\theta_{2}=1 / 2$ is optimal. For $k=3$, the exponent $\theta_{3}=1 / 6$ is conjectured to be optimal even for $M \geq \lambda_{3}^{-1}$ (see [4]). For $k \geq 5$, explicit better exponents can be produced (see for example [3] for an exposition of the recent results for $4 \leq k \leq 10$ ).

Proof of Theorem 1. By a classical series of transforms, the proof reduces to estimating the number $J_{s}(N)$ of solutions of

$$
\sum_{j=1}^{s}\left(x_{j}^{r}-y_{j}^{r}\right)=0 \quad(r=1,2,3) \quad 1 \leq x_{j}, y_{j} \leq N .
$$

The only novelty in the proof of Theorem 1 is the use of Wooley's recent breakthrough [5] where he proved Vinogradov's cubic conjecture, namely that for each integer $s \geq 1$ and each $\varepsilon>0$ one has

$$
J_{s}(N) \ll_{\varepsilon} N^{s+\varepsilon}+N^{2 s-6+\varepsilon} \quad(N \geq 1) .
$$

The preliminary transform of $S_{a, M}(f)$ is taken care of by the following result, which is a particular case of Lemme 1 of [3] with $k=4$.

Lemma 1 Let $a \in \mathbb{R}, M \in \mathbb{N}$ with $M \geq 10$. Let $0<\lambda_{4}<1 / 10$ be a real number and let $f:[a, a+M] \rightarrow \mathbb{R}$ be a $C^{4}$ function satisfying (1). Then setting $N:=\left\lfloor\lambda_{4}^{-1 / 5}\right\rfloor$, and with the notation (2), one has for each $s \geq 1$

$$
\left|S_{a, M}(f)\right|^{2 s} \ll_{s, C} M^{2 s} \lambda_{4}\left(1+\frac{1}{M \lambda_{4}}\right)\left(\frac{J_{s}(N)}{N^{2 s-6}}\right) \log M
$$

uniformly for $a \in \mathbb{R}, M \geq \lambda_{4}^{-3 / 5}$ and $f$ satisfying (1), where $J_{s}(N)$ has been defined in (4).

The proof of Theorem 1 is now straightforward : we use Lemma 1 with $s=6$, and we bound $J_{6}(N)$ using (5). This completes the proof of Theorem 1 . 


\section{References}

[1] O. Robert \& P. Sargos, A fourth derivative test for exponential sums, Compositio Math. 130 (2002) no 3, 275-292

[2] O. Robert, An analogue of van der Corput's $A^{5}$-process, Mathematika 49 (2002), 167-183

[3] O. Robert, Quelques paires d'exposants par la méthode de Vinogradov, J. Theor. Nombres Bordeaux 14 (2002), 271-285

[4] P. Sargos, Points entiers au voisinage d'une courbe, sommes trigonométriques courtes et paires d'exposants, Proc. London Math. Soc. (3) 70 (1995) 285-312

[5] T. D. Wooley, The cubic case of the main conjecture in Vinogradov's mean value theorem, arXiv:1401.3150

Olivier Robert

Université de Lyon and Université de Saint-Etienne

Institut Camille Jordan CNRS UMR 5208

23, rue du Dr P. Michelon

F-42000, Saint-Etienne, France

olivier.robert@univ-st-etienne.fr 